\title{
Effects of patient-controlled analgesia with hydromorphone or sufentanil on postoperative pulmonary complications in patients undergoing thoracic surgery: a quasi-experimental study
}

Guangming Yan ${ }^{1}$, Jie Chen ${ }^{1}$, Guiying Yang ${ }^{1}$, Guangyou Duan ${ }^{1}$, Zhiyong Du ${ }^{1}$, Zubin Y ${ }^{2}$, Jing Peng ${ }^{1}$, Wei Liao ${ }^{1}$ and Hong Li ${ }^{1 *}$

\begin{abstract}
Objective: To compare the analgesic effects of patient-controlled intravenous analgesia (PCA) with hydromorphone and sufentanil after thoracic surgery on postoperative pulmonary complications (PPCs).

Methods: A total of 142 patients who were scheduled for thoracic surgery were randomly allocated to receive PCA with hydromorphone (group A: experimental group): hydromorphone $0.2 \mathrm{mg} / \mathrm{kg}+$ dezocine $0.5 \mathrm{mg} / \mathrm{kg}+$ ramosetron $0.6 \mathrm{mg}$ diluted with normal saline to $200 \mathrm{~mL}$; or with sufentanil (group B: control group): sufentanil $3.0 \mu \mathrm{g} / \mathrm{kg}+$ dezocine $0.5 \mathrm{mg} /$ $\mathrm{kg}+$ ramosetron $0.6 \mathrm{mg}$ diluted with normal saline to $200 \mathrm{~mL}$. The parameters of intravenous analgesia pump were set as background dose $4 \mathrm{ml} / \mathrm{h}$, PCA dose $1 \mathrm{~mL}$, locking time $15 \mathrm{~min}$. Pain NRS (numerical rating scale), Ramsay sedation score, nausea or vomiting score were evaluated at $0 \mathrm{~h}, 6 \mathrm{~h}, 12 \mathrm{~h}, 24 \mathrm{~h}, 48 \mathrm{~h}$ after operation. The cases of PPCs (atelectasis, pulmonary infection, respiratory failure), CRP (C-reaction protein) and inflammatory cells (white cell count and percentage of neutrophils) and blood gas analysis at $12 \mathrm{~h}$ after operation, length of ICU and postoperative stay were recorded for each patient.
\end{abstract}

Results: Data of 136 patients were analyzed. Compared with group B (4[IQR:2,2]), the pain NRS in group A (2[IQR:4,4]) was significantly lower at $6 \mathrm{~h}$ after operation $(P=0.000)$. The $C R P$ in group $A(69.79 \pm 32.13 \mathrm{mg} / \mathrm{L})$ were lower than group $B(76.76 \pm 43.42 \mathrm{mg} / \mathrm{L})$ after operation, but the difference was not significant $(P=0.427)$. No difference of nausea or vomiting was found between group A $(7.3 \%)$ and group $B(5.8 \%)$ postoperatively $(P=0.999)$. The PPCs were happened in 11 patients in group A (16.2\%) and 22 patients in group B (32.4\%) and the difference between two groups was significant $(P=0.027)$. Seven patients in group $A(10.3 \%)$ and eighteen patients in group B (26.5\%) had clinical evidence of pneumonia and the difference between two groups was significant $(P=0.014)$. The length of $I C U$ and postoperative stay in group A were $2.73 \mathrm{~h}$ and 1.82 days less than group $B$ respectively but the differences were not significant $(P=0.234, P=0.186$ respectively).

Conclusion: Compared with sufentanil, hydromorphone may provide better postoperative analgesic effect with less pulmonary complications for patients undergoing thoracic surgery, and it may accelerate patients' rehabilitation.

Trial registration: Randomized Controlled Trials ChiCTR1800014282c. Registered 3 January 2018.

Keywords: Hydromorphone, Postoperative analgesia, Thoracic surgery, Postoperative pulmonary complications

\footnotetext{
*Correspondence: Ih78553@163.com

'Department of Anesthesiology, Anesthesiology of Xinqiao Hospital of Third

Military Medical University, Shapingba District, Chongqing 400037, China

Full list of author information is available at the end of the article
}

(C) The Author(s). 2018 Open Access This article is distributed under the terms of the Creative Commons Attribution 4.0 International License (http://creativecommons.org/licenses/by/4.0/), which permits unrestricted use, distribution, and

reproduction in any medium, provided you give appropriate credit to the original author(s) and the source, provide a link to the Creative Commons license, and indicate if changes were made. The Creative Commons Public Domain Dedication waiver (http://creativecommons.org/publicdomain/zero/1.0/) applies to the data made available in this article, unless otherwise stated. 


\section{Introduction}

For patients undergoing thoracotomy, postoperative pulmonary complications (PPCs) including atelectasis, pulmonary infection and respiratory failure, which were induced by postoperative respiratory dysfunction, were strongly associated with the increase of mortality and postoperative hospital stays, accounting for up to $84 \%$ of all deaths $[1,2]$. Multiple risk factors are responsible, including the extensive tissue destruction, one lung ventilation and pro-inflammatory cytokines [3]. Patients were not allowed to take deep breath or cough with poor control of postoperation pain and this may lead to atelectasis and retention of secretion [4]. Previous studies have demonstrated that satisfactory postoperative pain relief can enhance patients' recovery after surgery with better surgical outcomes, less complications and shorter length of hospital stay [5]. So effective management of acute pain after thoracotomy was necessary.

Various strategies had been used for thoracotomy pain management including epidural analgesia, intercostals nerve blockade and systemic opioids like morphine, fentanyl, sufentanil, etc. However, epidural analgesia and intercostals nerve blockade were associated with a considerable risk of sympatholytic complications, misplace, epidural hematoma and abscesses [6-8]. Nowadays, systemic opioids still play an important role in the commonly strategies of patientcontrolled intravenous analgesia for thoracic surgery. However, sufentanil can cause some adverse complications such as respiratory depression, which affect safety and recovery of patients [9].

On the other hand, as a potent opioid analgesics, hydromorphone relieves pain through exciting the $\mu$ opioid receptor of the central nervous system [10]. It was reported that compared with sufentanil, hydromorphone offered satisfactory postoperative pain therapy with moderate respiratory insufficiency [11, 12]. Therefore, we hypothesized hydromorphone may provide better postoperative analgesia effect with less pulmonary complications for patients undergoing thoracic surgery.

Additionally, multimode Analgesia which combines different methods to enhance the efficiency of analgesic and reduce adverse event is generally accepted. Dezocine was thought as a $\mu$-receptor agonist and a K-receptor antagonist with a "ceiling effect" for respiratory depression, which could decrease analgesic requirement and attenuate allodynia [13, 14]. The combination of hydromorphone and dezocine may enhance postoperative analgesia after thoracotomy.

Based on the above information, this study aimed to investigate the effects of hydromorphone and sufentanil combining with dezocine on the incidence of PPCs and patient's outcome.

\section{Materials and methods}

\section{Patients}

After taking institutional ethics committee (The second affiliated hospital, The Third Military Medical University, Chongqing, China) approval, the trial was registered after patient enrollment at Chinese Clinical Trial Registry, http:// www.chictr.org.cn/listbycreater.aspx (ChiCTR1800014282c, January 3, 2018). Written informed consent was obtained from all enrolled patients. From December 2017 to March 2018, a total of 142 patients who were scheduled for elective thoracic surgery, aged 20 to 65 years, with American Society of Anesthesiologists (ASA) physical status I or II were recruited. Exclusion criteria included history of severe heart, hepatic or renal disease, pre-existing of lung disease (chronic obstructive pulmonary disease with forced expiratory volume in one second of predicted and/or over forced vital capacity ratio less than 0.8 and/or 0.7 respectively, pneumonia or atelectasis), preoperative respiratory failure $\left(\mathrm{PO}_{2}<60 \mathrm{mmHg}\right.$ or $\left.\mathrm{PCO}_{2}>50 \mathrm{mmHg}\right)$, allergy to the studied drugs, and history of chronic pain condition or opioid use.

\section{Study design}

On the day before operation, all included patients without premedication were informed the study procedure after written informed consent was obtained. And the use of numerical rating scale (NRS) for evaluation of pain intensity which graduated from 0 (no pain) to 10 (worst pain) was explained to patients. Simple randomization schedule was performed and randomization number was generated using SPSS 19.0 (SPSS Inc., Chicago, IL). The patients were randomly allocated into 2 groups by using opaque sealed envelopes containing the computer-generated randomization schedule (Fig. 1). In the study, patients were blinding to the group allocation. Also, the involved anesthesiologists and surgeons during the surgery and the investigator who performed the postoperative follow-up were not aware of the group allocation. All data and experiment were carried out under the supervision of Data and Safety Monitoring Board.

\section{Anesthetic procedure}

Monitoring of patients during the surgery was accomplished by electrocardiogram (ECG), pulse oximetry $\left(\mathrm{SpO}_{2}\right)$, the radial artery catheter placement, mean arterial pressure (MAP), end-tidal carbon dioxide $\left(\mathrm{ET}_{\mathrm{C}} \mathrm{CO}_{2}\right)$ and bispectralindex (BIS). General anesthesia was induced by intravenous injection with midazolam $(0.1 \mathrm{mg} /$ $\mathrm{kg})$, atracurium $(0.15 \mathrm{mg} / \mathrm{kg})$, propofol $(2-3 \mathrm{mg} / \mathrm{kg})$, sufentanil $(0.4 \mu \mathrm{g} / \mathrm{kg})$, and tracheal intubation with a double-lumen tube of appropriate size. Anesthesia was maintained with sevoflurane(1-2\%), propofol $(6-8 \mathrm{mg} / \mathrm{kg} /$ $\mathrm{h})$, remifentanil(0.5-1 $\mathrm{gg} / \mathrm{kg} / \mathrm{min})$, and atracurium as necessary. Patients were mechanically ventilated with $8 \mathrm{ml} /$ 


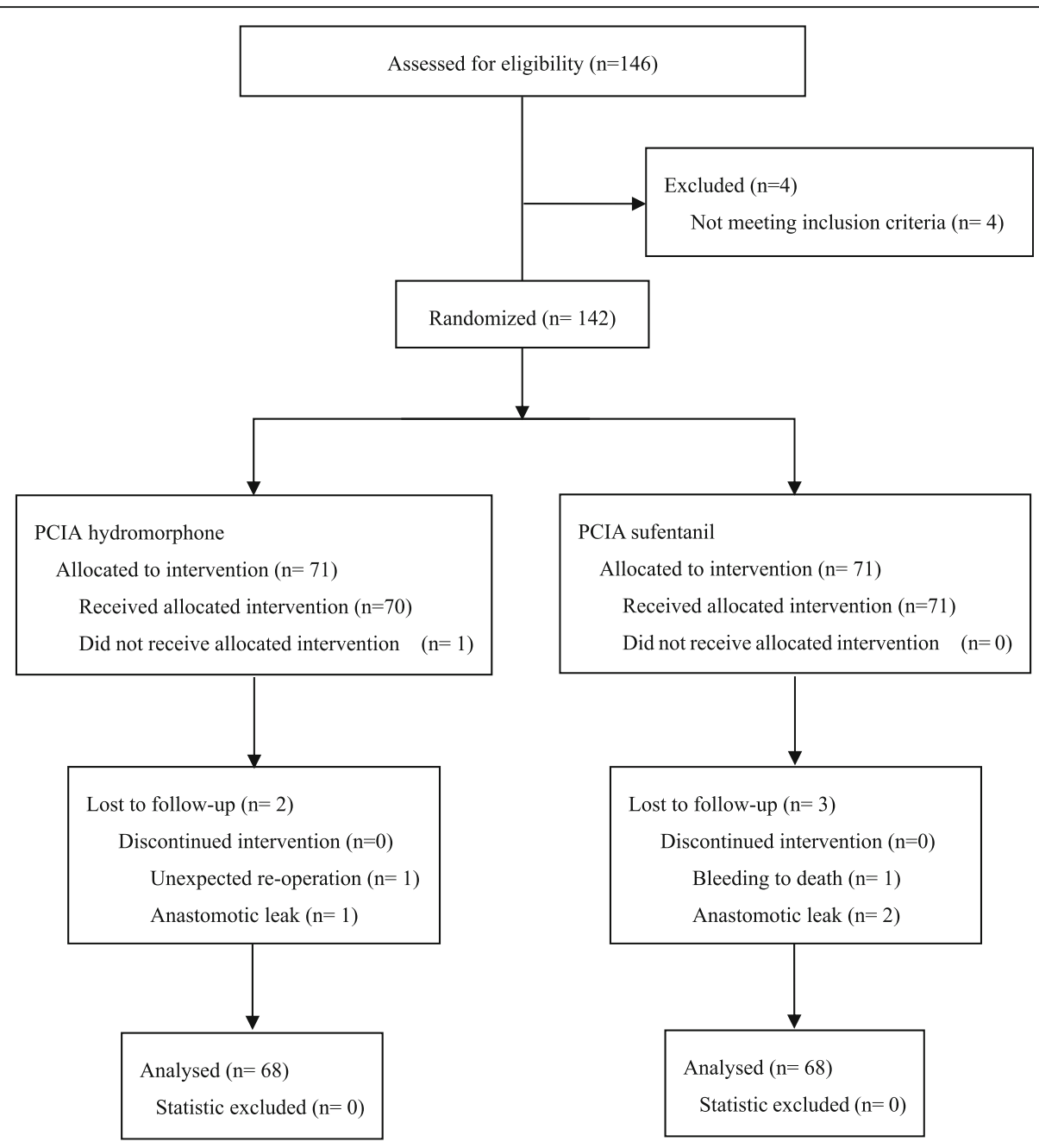

Fig. 1 Participant flow. PCIA = patient-controlled intravenous analgesia

$\mathrm{kg}$ during two lung ventilations, reduced to $5 \mathrm{ml} / \mathrm{kg}$ with $5 \mathrm{cmH}_{2} \mathrm{O}$ PEEP during one-lung ventilation and the frequency was adjusted to keep the end tidal carbon dioxide $\left(\mathrm{ETCO}_{2}\right)$ between 35 and $45 \mathrm{mmHg}$ [15]. The inspired oxygen fraction $\left(\mathrm{FiO}_{2}\right)$ was increased if necessary to maintain oxygen saturations $\left(\mathrm{SPO}_{2}\right)$ greater than 90\%. Alveolar recruitment strategy: the PEEP was increased from $5 \mathrm{cmH}_{2} \mathrm{O}$ to $40 \mathrm{cmH}_{2} \mathrm{O}$ by a level of 5 $\mathrm{cmH}_{2} \mathrm{O}$ at a ventilatory frequency of $8 \mathrm{bpm}$ with a tidal volume of $7-8 \mathrm{ml} / \mathrm{kg}$ until the alveolar recruited, and then reduced to previous $5 \mathrm{cmH}_{2} \mathrm{O}$ gradually [16].

For all included patients, operations were done by the same experienced surgeons. After the end of the skin closure, all patients were given sufentanil $(0.1 \mu \mathrm{g} / \mathrm{kg})$, Ramosetron $(0.3 \mathrm{mg})$, and if patients reported the pain-NRS $\geq 4$, followed by $5 \mathrm{mg}$ boluses dezocine.

Postoperative pain management.

Mechanical intravenous analgesia pump $(200 \mathrm{~mL}$, Beijing KSH Technology Institute, Beijing, China) was used and parameters were set as background dose $4 \mathrm{ml} /$ h, PCA dose $1 \mathrm{ml}$, locking time $15 \mathrm{~min}$. In the hydromorphone (HUMANWELL HEALTHCARE, Hubei, China) group (group A) PCA with a mixture of hydromorphone $(0.2 \mathrm{mg} / \mathrm{kg})$, dezocine $(0.5 \mathrm{mg} / \mathrm{kg}$, Yangtze River Pharmaceutical, China), and ramosetron $0.6 \mathrm{mg}$ was applied. While in sufentanil (HUMANWELL HEALTHCARE, Hubei, China) group (group B) PCA with a compound of sufentanil $(3.0 \mu \mathrm{g} / \mathrm{kg})$, dezocine $(0.5$ $\mathrm{mg} / \mathrm{kg}$ ), and ramosetron $(0.6 \mathrm{mg})$ was used. During the PCA treatment, when inadequate analgesia presented, rescue analgesia was given suing dezocine $5 \mathrm{mg}$.

Outcomes.

PPCs evaluation was performed by an independent and experienced surgeon after surgery at the same time each day up to discharge. Using the Melbourne Group Scale (MGS), PPCs was defined in those patients presenting with four or more of the following eight dichotomous factors: temperature $>38^{\circ} \mathrm{C}$; white cell count $>11.2 \times 10^{9} / \mathrm{L}$; 
chest X-ray findings of atelectasis or consolidation; signs of infection on sputum microbiology; purulent sputum; physician diagnosis of pneumonia; $\mathrm{SPO} 2<90 \%$ on air; and prolonged intensive care (ICU) or hospital stay [17]. Respiratory failure was defined according to artery gas analysis $\left(\mathrm{PO}_{2}<60 \mathrm{mmHg}\right.$ or $\left.\mathrm{PCO}_{2}>50 \mathrm{mmHg}\right)$ when patients respired air [18].

Rest pain NRS was considered as the secondary outcome. In addition, demographic data including age, weight, smoking index (the number of cigarettes smoked per day multiply by number of years of smoking) [19], and artery blood gas analysis were recorded before operation. Intraoperatively, duration of surgery, total dose of remifentanil and sufentanil were recorded. Pain NRS (0, no pain to 10 , worst pain), Ramsay sedation score (1, anxious, agitated, or restless; 2 , cooperative, oriented, and tranquil; 3 , response to command; 4, brisk response; 5 , a sluggish response; 6 , no response) and nausea or vomiting score ( 0 , without nausea or vomiting; 1 , mild; 2 , middle; 3 , serious) were collected at $0 \mathrm{~h}, 6 \mathrm{~h}, 12 \mathrm{~h}, 24 \mathrm{~h}, 48 \mathrm{~h}$ after extubation [20]. The skin pruritus was divided as mild, middle and server. CRP (C-reaction protein), inflammatory cells and blood gas analysis at $12 \mathrm{~h}$ after operation were also measured. And length of ICU and postoperative stay was recorded.

\section{Statistical analysis}

The primary outcome of the current study was the incidence of PPCs. Previously published data have showed that the incidence of PPCs was 28\% [21]. On the basis of preliminary experimental data, we hypothesized hydromorphone may reduce the odds of pulmonary complications to $15 \%$. Under these conditions, 56 patients per group were required to reach a power of $80 \%$ (one-side hypothesis) and a 0.05 risk of type I error. Thus, considering about 20\% loss of follow-up, we decided to include 71 evaluable patients for each group.

Date were presented as number, percentages, median (range) or mean \pm SD and analyzed using the SPSS 19.0 software. Chi-square test was used to compare the difference of categorical data between two groups. The difference of pain NRS between two groups was compared by the use of two independent samples nonparametric test (the Mann-Whitney test). Independent samples $\mathrm{t}$-test was used to compare the continuous variable data between 2 groups. Two side $P$-value $<0.05$ was considered to be statistically significant.

\section{Result}

\section{General results}

After exclusion of one patient (the patient in the hydromorphone group because of failure to receive allocated intervention), 141 patients were considered of analysis. Then, five patients were excluded for unexpected re operation, anastomotic leak or bleeding to death (Fig. 1). Thus, the pain NRS and PPCs analyses were based on 68 patients in the hydromorphone group and 68 patients in the sufentanil group.

As shown in Table 1, no difference was found in age, height, weight, gender, smoking index, surgery types,

Table 1 Demographic data and patients' characteristics

\begin{tabular}{|c|c|c|c|}
\hline & Group A $(n=68)$ & Group B $(n=68)$ & $P$-value \\
\hline Age (yr) & $51.03 \pm 10.02$ & $48.37 \pm 11.09$ & 0.144 \\
\hline Height (cm) & $162.74 \pm 7.35$ & $163.83 \pm 9.11$ & 0.442 \\
\hline Gender (F/M) & $29 / 39$ & $27 / 41$ & 0.727 \\
\hline Weight (kg) & $61.35 \pm 7.64$ & $60.69 \pm 8.08$ & 0.621 \\
\hline Smoking index & $197.94 \pm 349.10$ & $207.35 \pm 281.83$ & 0.863 \\
\hline Duration of surgery (min) & $178.51 \pm 75.22$ & $179.69 \pm 68.08$ & 0.924 \\
\hline Total amount of sufentanil $(\mu \mathrm{g})$ & $62.97 \pm 14.16$ & $60.59 \pm 13.86$ & 0.323 \\
\hline Total amount of remifentanil (mg) & $1.18 \pm 0.60$ & $1.29 \pm 0.68$ & 0.329 \\
\hline Type of surgery & & & 1.000 \\
\hline Thoracoscopic & 54 & 54 & \\
\hline Open Esophagectomy & 14 & 14 & \\
\hline Total amount of fluid use (mL) & $1559.85 \pm 588.93$ & $1538.53 \pm 512.87$ & 0.891 \\
\hline White cell count $\left(10^{9} / \mathrm{L}\right)$ & $6.00 \pm 2.20$ & $6.18 \pm 2.21$ & 0.643 \\
\hline Percentage of neutrophils (\%) & $61.81 \pm 10.05$ & $60.08 \pm 10.67$ & 0.340 \\
\hline $\mathrm{PH}$ & $7.42 \pm 0.05$ & $7.43 \pm 0.03$ & 0.202 \\
\hline $\mathrm{PO}_{2}(\mathrm{mmHg})$ & $85.38 \pm 11.15$ & $84.45 \pm 12.36$ & 0.648 \\
\hline $\mathrm{PCO}_{2}(\mathrm{mmHg})$ & $40.63 \pm 4.31$ & $40.46 \pm 3.52$ & 0.808 \\
\hline
\end{tabular}

Smoking index = the number of cigarettes smoker per day multiply by number of years of smoking. Total amount of fluid use = Fluid therapy during surgery (crystalloid and colloid). Data given as mean \pm SD or number of patients 
preoperative inflammatory cells and blood gas analysis, intraoperative dose of remifentanil and sufentanil, and duration of the surgery between patients in group $\mathrm{A}$ and group B $(P>0.05)$.

\section{Postoperative analgesic effects and consumption of analgesics}

Pain NRS and Ramsay sedation scores were measured at $0 \mathrm{~h}, 6 \mathrm{~h}, 12 \mathrm{~h}, 24 \mathrm{~h}$, and $48 \mathrm{~h}$ after the surgery. The results showed that pain NRS at $6 \mathrm{~h}$ after the surgery in group A was significantly higher than that in group B $(P<0.05)$, and there was no difference in pain NRS at other time points between two groups $(P>0.05$, Fig. 2$)$. No significant difference of Ramsay sedation score was observed between two groups $(P>0.05$, Table 2$)$. In addition, there was no significant difference in consumption of analgesics for patients during PCA between two groups $(P>0.05$, Table 3$)$.

\section{Adverse events assessment}

The side-effects of nausea or vomiting were complained mainly at $6 \mathrm{~h}$ and 12 after surgery, but the difference between two groups was not significant at all time points postoperatively $(P>0.05$, Table 4$)$. In addition, skin pruritus was not observed in all patients.

\section{Plasma CRP and blood gas analysis}

Analysis of variance showed that plasma CRP level in group B was not significantly higher than that in group A $(P>0.05$, Table 5). There was no significant difference between two groups in White cell count, Percentage of neutrophils, $\mathrm{pH}, \mathrm{PO}_{2}(\mathrm{mmHg}), \mathrm{PCO}_{2}(\mathrm{mmHg})$ and $\mathrm{BE}$ value at $12 \mathrm{~h}$ after operation $(P>0.05$, Table 5$)$.

\section{Primary outcomes}

The incidence of PPCs including pneumonia, atelectasis and respiratory failure in group A was lower than group $B$, and the difference between two groups was significant $(P=0.027$, Table 6$)$. The length of ICU and postoperative

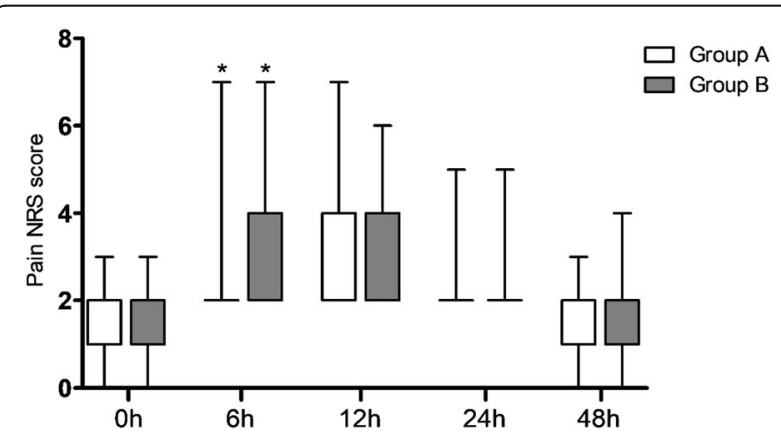

Fig. 2 Pain NRS (numerical rating scale) distribution in both the groups at $0 \mathrm{~h}(\mathrm{~A}), 6 \mathrm{~h}(\mathrm{~B}), 12 \mathrm{~h}(\mathrm{C}), 24(\mathrm{D})$ and $48 \mathrm{~h}(\mathrm{E})$ after surgery. (* represented significant difference between group $A$ and group $B$ )
Table 2 Ramsay sedation scores at 0 h, 6 h, 12 h, 24 h, and 48 h after the surgery

\begin{tabular}{|c|c|c|c|c|c|c|c|c|c|c|c|c|c|c|c|}
\hline & \multicolumn{3}{|l|}{$\mathrm{Oh}$} & \multicolumn{3}{|c|}{$6 \mathrm{~h}$} & \multicolumn{3}{|c|}{$12 \mathrm{~h}$} & \multicolumn{3}{|c|}{$24 \mathrm{~h}$} & \multicolumn{3}{|c|}{$48 \mathrm{~h}$} \\
\hline & 0 & 1 & 2 & 0 & 1 & 2 & 0 & 1 & 2 & 0 & 1 & 2 & 0 & 1 & 2 \\
\hline $\begin{array}{l}\text { Group A } \\
(n=68)\end{array}$ & 66 & 2 & 0 & 65 & 1 & 2 & 66 & 2 & 0 & 68 & 0 & 0 & 68 & 0 & 0 \\
\hline $\begin{array}{l}\text { Group B } \\
(n=68)\end{array}$ & 67 & 1 & 0 & 68 & 0 & 0 & 67 & 0 & 1 & 67 & 1 & 0 & 68 & 0 & 0 \\
\hline$P$ value & 0.9 & & & 0.2 & & & 0.22 & & & 0.9 & & & 1.00 & & \\
\hline
\end{tabular}

stay in group A were less than group B respectively but the differences were not statistically significant $(P>0.05$, Table 7).

\section{Discussion}

This study used a double blind randomized controlled design to investigate the efficacy of PCA with hydromorphone in the prevention of postoperative pulmonary complication compared with sufentanil. The results showed that hydromorphone may provide better postoperative analgesia and anti-inflammatory effect with less pulmonary complications and accelerate patients' rehabilitation for patients undergoing thoracic surgery.

By stimulating the $\mu$ opioid receptor of the central nervous system, hydromorphone played an important role in analgesia, especially in acute pain treatment $[5,10]$. The equi-analgesic ratio for morphine to hydromorphone was reported between 5:1-7:1 [22]. Sufentanil was often reported to be about 400-1000 times more than morphine [23]. Chun-Shan Dong et al. reported that $3.0 \mu \mathrm{g} / \mathrm{kg}$ sufentanil can improve pain control after thoracotomy [24]. Therefor choosing the appropriate potency ratio (50:1), hydromorphone $0.2 \mathrm{mg} / \mathrm{kg}$ can be considered equipotent to sufentanil $3.0 \mu \mathrm{g} / \mathrm{kg}$.

Compared to group sufentanil, the pain NRS at $6 \mathrm{~h}$ after operation in group hydromorphone was significantly lower. The median protein binding of hydromorphone is $11.6 \%$ with the free fraction remaining nearly constant, whereas the protein binding of sufentanil was $88.4 \%$ with the free fraction increasing towards the end of the PCA period [12]. Thus, in the early period of the PCA, the analgesic effect of hydromorphone was better than sufentanil.

The level of CRP (C-reactive protein) in plasma increases greatly during acute phase response to tissue injury, infection, or other inflammatory stimuli [25].

Table 3 The consumption of analgesics at $1 d$, and $2 d$ after the surgery

\begin{tabular}{llll}
\hline & Group A $(n=68)$ & Group B $(n=68)$ & $P$ value \\
\hline $1 \mathrm{~d}(\mathrm{~mL})$ & $100.74 \pm 5.52$ & $101.20 \pm 6.72$ & 0.697 \\
$2 \mathrm{~d}(\mathrm{~mL})$ & $95.74 \pm 3.93$ & $95.00 \pm 4.75$ & 0.380 \\
\hline
\end{tabular}


Table 4 nausea or vomiting scores at $0 \mathrm{~h}, 6 \mathrm{~h}, 12 \mathrm{~h}, 24 \mathrm{~h}$, and $48 \mathrm{~h}$ after the surgery

\begin{tabular}{|c|c|c|c|c|c|c|c|c|c|c|c|c|c|c|}
\hline & \multicolumn{3}{|l|}{$\mathrm{Oh}$} & \multicolumn{3}{|l|}{$6 \mathrm{~h}$} & \multicolumn{3}{|c|}{$12 \mathrm{~h}$} & \multicolumn{3}{|c|}{$24 \mathrm{~h}$} & \multicolumn{2}{|c|}{$48 \mathrm{~h}$} \\
\hline & 0 & 1 & 2 & 0 & 1 & 2 & 0 & 1 & 2 & 0 & 1 & 2 & 0 & 12 \\
\hline $\begin{array}{l}\text { Group A } \\
(n=68)\end{array}$ & 68 & 0 & 0 & 65 & 2 & 1 & 66 & 1 & 1 & 67 & 1 & 0 & 68 & 0 \\
\hline $\begin{array}{l}\text { Group B } \\
(n=68)\end{array}$ & 68 & 0 & 0 & 66 & 1 & 1 & 66 & 2 & 0 & 68 & 0 & 0 & 68 & 0 \\
\hline$P$ value & 1.00 & & & 0.8 & & & 0.31 & & & 0.99 & & & 1.00 & \\
\hline
\end{tabular}

Khaled M. Fares et al. found that pro-inflammatory cytokines increased to their zenith at $1 \mathrm{~h}$ after Esophagectomy [21].There were significant inverse correlations between pain intensity and the plasma inflammatory cytokines concentrations [26]. Comparing with group sufentanil, the CRP was lower in group hydromorphone. One possible explanation of this was that the analgesic effect of hydromorphone was better than sufentanil in the early period of the PCA. But the difference between the two groups was not significant. Carvalho, B et al. reported that hydromorphone cannot reduce wound exudate concentrations of interleukin- 6 and interleukin-10 [27]. Further research with more inflammatory cytokines measurement was necessary.

The major cause of postoperative morbidity and mortality after thoracotomy is PPCs, and inadequate postoperative analgesia can result in splinting, retention of secretions and atelectasis and further may compromise the respiratory functions [1]. Pulmonary function was severely decreased to $39 \%$ of the basic line on the first day and rehabilitated gradually [28]. The incidence of PPCs may be reduced by a better postoperative analgesia with a lower respiratory depression [29]. Jeleazcov, C et al. found that PCA with hydromorphone offered satisfactory postoperative analgesic with respiratory insufficiency in 5\% of the patients [11]. Correspondingly, Deng, $\mathrm{C}$ et al. had reported that the risks of respiratory depression in patients undergoing colonoscopy was 33\% by using sufentanil as a perioperative analgesia [30]. As

Table 5 Plasma CRP and blood gas analysis at $12 \mathrm{~h}$ after operation

\begin{tabular}{llll}
\hline & $\begin{array}{l}\text { Group A } \\
(\mathrm{n}=68)\end{array}$ & $\begin{array}{l}\text { Group B } \\
(\mathrm{n}=68)\end{array}$ & P value \\
\hline CRP $(\mathrm{mg} / \mathrm{L})$ & $69.79 \pm 32.13$ & $76.76 \pm 43.42$ & 0.427 \\
White cell count $\left(10^{9} / \mathrm{L}\right)$ & $9.49 \pm 2.83$ & $10.55 \pm 3.43$ & 0.056 \\
Percentage of neutrophils $(\%)$ & $75.94 \pm 8.38$ & $78.50 \pm 6.54$ & 0.051 \\
$\mathrm{PH}$ & $7.39 \pm 0.03$ & $7.40 \pm 0.04$ & 0.377 \\
$\mathrm{PO}_{2}(\mathrm{mmHg})$ & $114.15 \pm 26.93$ & $113.75 \pm 36.02$ & 0.942 \\
$\mathrm{PCO}_{2}(\mathrm{mmHg})$ & $43.09 \pm 4.35$ & $42.58 \pm 7.52$ & 0.509 \\
$\mathrm{BE}$ & $1.61 \pm 2.52$ & $2.41 \pm 2.38$ & 0.062 \\
\hline CRP C-reactive protein & & &
\end{tabular}

CRP C-reactive protein
Table 6 primary outcomes

\begin{tabular}{llll}
\hline & Group A $(n=68)$ & Group B $(n=68)$ & $P$ value \\
\hline pneumonia & $7(10.3 \%)$ & $18(26.5 \%)$ & 0.014 \\
atelectasis & $8(11.8 \%)$ & $6(8.8 \%)$ & 0.572 \\
respiratory failure & $0(0 \%)$ & $1(1.5 \%)$ & 0.315 \\
Pneumonia and atelectasis & $4(5.9 \%)$ & $3(4.4 \%)$ & 0.697 \\
Number of PPCs & $11(16.2 \%)$ & $22(32.4 \%)$ & 0.027 \\
\hline
\end{tabular}

PPCs postoperative pulmonary complications (pneumonia, atelectasis and respiratory failure)

mentioned above, hydromorphone also had a quicker therapeutic and better anti-inflammatory effect comparing with sufentanil. So, our results of postoperative pulmonary complications were consistent with this explanation. With respect to outcomes, we observed a significant decrease of pneumonia and a better trend of length of ICU and postoperative stay in group hydromorphone, even if the difference of length of ICU and postoperative stay between both groups was statistically insignificant.

Dezocine was regard as a partial $\mu$-receptor agonist, a k-receptor antagonist, and a norepinephrine and serotonin reuptake inhibitor [31]. Recently another research suggested that dezocine can attenuate allodynia by spinal $\mu$-opioid receptor antagonism or norepinephrine depletion/ $\alpha 2$-adrenoceptor antagonism [14]. A Meta-Analysis of Randomized Controlled Trials suggested that Dezocine was a promising analgesic for preventing postoperative pain [32]. Wang, $C$ et al. had reported that combined dezocine and sufentanil might be a complement drug for sufentanil in PCA with limited side effects [19]. Another research reports that sufentanil may increase the contractile tension of intestine smooth muscle, while dezocine does not [33]. Our study indicated that dezocine can be safely used with hydromorphone in PCA after thoracotomy without increasing the adverse reaction.

\section{Study limitations}

The different surgical trauma and combined application of various analgesics may become potential factors that interfere with the results of our study. And also, the insignificant difference of the length of ICU and postoperative stay may be limited by its sample size. Concerning of the limitations of our study, further innovative strategies will be required to investigate the specific effect of hydromorphone on lung function.

Table 7 The ICU stay and length of postoperative stay

\begin{tabular}{llll}
\hline & Group A $(n=68)$ & Group B $(n=68)$ & $P$ value \\
\hline ICU stay (h) & $57.75 \pm 13.71$ & $60.48 \pm 12.96$ & 0.234 \\
Postoperative stay(d) & $9.06 \pm 3.38$ & $10.88 \pm 7.17$ & 0.186 \\
\hline
\end{tabular}

ICU intensive care unit 


\section{Conclusion}

In conclusion, we have found that the pain relief in the hydromorphone group was observed to result in better outcomes including lesser PPCs, and shorter length of the ICU and postoperative stay. Thus, hydromorphone may be suitable opioid to patient-controlled intravenous analgesia for patients undergoing thoracotomy.

\section{Abbreviations}

ASA: American Society of Anesthesiologists; BIS: Bispectralindex; CRP: Creaction protein; ICU: Intensive care unit; MGS: Melbourne Group Scale; NRS: Numerical rating scale; PCA: Patient-controlled intravenous analgesia; PEEP: Positive end-expiratory pressure.; PPCs: Postoperative pulmonary complications

\section{Acknowledgements}

We thank Dr. Zubin Yu, Department of Thoracic Surgery, for his assistance in the evaluation of postoperative pulmonary complications.

\section{Funding}

This work was supported by the General Program of National Natural Science Foundation of China (81571870). None of the authors has been funded by any organization with a real or potential interest in the subject matter materials, equipment, or devices.

\section{Availability of data and materials}

The datasets generated and analyzed during the current study are not publicly available due to the institutional restrictions but are available from the corresponding author on reasonable request.

\section{Authors' contributions}

GY contribute to Research Design, Data Collection, Data Analysis and Paper Writing. JC contribute to Data Collection. GY contribute to Data Collection. GD contribute to Data Analysis. ZD contribute to Data Collection and Data Analysis. ZY contribute to Data Collection. JP contribute to Data Collection. WL contribute to Data Collection. HL contribute to Research Design and Paper Writing. All authors read and approved the final manuscript.

\section{Ethics approval and consent to participate}

This research was approval by institutional ethics committee of the second affiliated hospital of The Third Military Medical University and the trial was registered after patient enrollment at Chinese Clinical Trial Registry, http:// www.chictr.org.cn/listbycreater.aspx (ChiCTR1800014282c, January 3, 2018). Written informed consent was obtained from all enrolled patients.

\section{Consent for publication}

Not applicable.

\section{Competing interests}

The authors declare no competing interests.

\section{Publisher's Note}

Springer Nature remains neutral with regard to jurisdictional claims in published maps and institutional affiliations.

\section{Author details}

'Department of Anesthesiology, Anesthesiology of Xinqiao Hospital of Third Military Medical University, Shapingba District, Chongqing 400037, China. ${ }^{2}$ Department of Anesthesiology, Xinqiao Hospital, Shapingba District, Thoracic Surgery of Xinqiao Hospital of Third Military Medical University, Chongqing 400037, China.

Received: 11 June 2018 Accepted: 30 November 2018 Published online: 19 December 2018

\section{References}

1 Khuri SF, Henderson WG, Depalma RG, et al. Determinants of long-term survival after major surgery and the adverse effect of postoperative complications. Ann Surg. 2005;242:326-41 341-343.
2 Agostini P, Cieslik H, Rathinam S, et al. Postoperative pulmonary complications following thoracic surgery: are there any modifiable risk factors? Thorax. 2010;65:815-8.

3 Michelet $P$, D'Journo XB, Roch $A$, et al. Protective ventilation influences systemic inflammation after esophagectomy: a randomized controlled study. Anesthesiology. 2006;105:911-9.

4 Xue FS, Li BW, Zhang GS, et al. The influence of surgical sites on early postoperative hypoxemia in adults undergoing elective surgery. Anesth Analg. 1999:88:213-9.

5 Zhu Y, Jing G, Yuan W. Preoperative administration of intramuscular dezocine reduces postoperative pain for laparoscopic cholecystectomy. J Biomed Res. 2011;25:356-61.

6 Biswas S, Verma R, Bhatia VK, et al. Comparison between thoracic epidural block and thoracic paravertebral block for post thoracotomy pain relief. J Clin Diagn Res. 2016:10:C8-C12.

7 Sundary MT. Epidural catheter misplaced into the thoracic cavity: utilized to provide interpleural analgesia. Anesth Essays Res. 2015:9:121-3.

8 Kupersztych-Hagege E, Dubuisson E, Szekely B, et al. Epidural hematoma and abscess related to thoracic epidural analgesia: a single-center study of 2,907 patients who underwent lung surgery. J Cardiothorac Vasc Anesth. 2017:31:446-52

9 Zhou Y, Huang JX, Lu XH, et al. Patient-controlled intravenous analgesia for non-small cell lung cancer patient after thoracotomy. J Cancer Res Ther. 2015;11(Suppl 1):C128-30.

10 Felden L, Walter C, Harder S, et al. Comparative clinical effects of hydromorphone and morphine: a meta-analysis. Br J Anaesth. 2011;107:319-28.

11 Jeleazcov C, Ihmsen H, Saari Tl, et al. Patient-controlled analgesia with target-controlled infusion of hydromorphone in postoperative pain therapy. Anesthesiology. 2016;124:56-68.

12 Saari $\mathrm{Tl}$, Ihmsen $\mathrm{H}$, Mell J, et al. Influence of intensive care treatment on the protein binding of sufentanil and hydromorphone during pain therapy in postoperative cardiac surgery patients. Br J Anaesth. 2014;113:677-87.

13 Liu R, Huang XP, Yeliseev A, et al. Novel molecular targets of dezocine and their clinical implications. Anesthesiology. 2014;120:714-23.

14 Wang YX, Mao XF, Li TF, et al. Dezocine exhibits antihypersensitivity activities in neuropathy through spinal mu-opioid receptor activation and norepinephrine reuptake inhibition. Sci Rep. 2017;7:43137.

15 Michelet $\mathrm{P}, \mathrm{D}^{\prime}$ Journo XB, Roch $\mathrm{A}$, et al. Protective ventilation influences systemic inflammation after esophagectomy: a randomized controlled study. Anesthesiology. 2006;105:911-9.

16 Tusman G, Bohm SH, Vazquez DAG, et al. 'Alveolar recruitment strategy' improves arterial oxygenation during general anesthesia. Br J Anaesth. 1999; 82:8-13.

17 Agostini P, Cieslik H, Rathinam S, et al. Postoperative pulmonary complications following thoracic surgery: are there any modifiable risk factors? Thorax. 2010;65:815-8.

18 Campbell EJ. respiratory failure[J]. Br Med J. 1965;1(5448):1451-60.

19 Su J, Qin Y, Shen C, et al. Association between smoking/smoking cessation and glycemic control in male patients with type 2 diabetes. Zhonghua Liu Xing Bing Xue Za Zhi. 2017;38:1454-9.

20 Wang $\mathrm{C}$, Li L, Shen B, et al. A multicenter randomized double-blind prospective study of the postoperative patient controlled intravenous analgesia effects of dezocine in elderly patients. Int J Clin Exp Med. 2014;7:530-9.

21 Meierhenrich R, Hock D, Kuhn S, et al. Analgesia and pulmonary function after lung surgery: is a single intercostal nerve block plus patient-controlled intravenous morphine as effective as patient-controlled epidural anaesthesia? A randomized non-inferiority clinical trial [J]. Br J Anaesth. 2011;106(4):580-9.

22 Murray A, Hagen NA. Hydromorphone. J Pain Symptom Manag. 2005;29(5 Suppl):S57-66

23 Cafiero T, Di Minno RM, Sivolella G, et al. Immediate postoperative pain management in patients undergoing major abdominal surgery after remifentanil-based anesthesia: sufentanil vs tramadol. Minerva Anestesiol. 2004;70:661-9.

24 Dong CS, Zhang J, Lu Q, et al. Effect of Dexmedetomidine combined with sufentanil for post- thoracotomy intravenous analgesia:a randomized, controlled clinical study. BMC Anesthesiol. 2017;17:33.

25 Xiang $\mathrm{D}$, Xing $\mathrm{H}$, Tai $\mathrm{H}$, et al. Preoperative C-reactive protein as a risk factor for postoperative delirium in elderly patients undergoing laparoscopic surgery for Colon carcinoma. Biomed Res Int. 2017;2017:5635640. 
26 Zin CS, Nissen LM, O'Callaghan JP, et al. Preliminary study of the plasma and cerebrospinal fluid concentrations of IL-6 and IL-10 in patients with chronic pain receiving intrathecal opioid infusions by chronically implanted pump for pain management. Pain Med. 2010;11:550-61.

27 Carvalho B, Lemmens HJ, Ting V, et al. Postoperative subcutaneous instillation of low-dose ketorolac but not hydromorphone reduces wound exudate concentrations of interleukin- 6 and interleukin-10 and improves analgesia following cesarean delivery. J Pain. 2013;14:48-56.

28 Cui YS, Zhang ZY, Ayidu AB. Early postoperative pulmonary function study: changing curve and influencing factors analysis. Zhonghua Wai Ke Za Zhi. 2003:41:909-12.

29 Richardson J, Sabanathan S, Shah R. Post-thoracotomy spirometric lung function: the effect of analgesia. A review. J Cardiovasc Surg (Torino). 1999; 40:445-56.

30 Deng C, Wang X, Zhu Q, et al. Comparison of nalbuphine and sufentanil for colonoscopy: a randomized controlled trial. PLoS One. 2017;12:e188901.

31 Liu R, Huang XP, Yeliseev A, et al. Novel molecular targets of dezocine and their clinical implications. Anesthesiology. 2014;12:714-23.

32 Zhou X, Zhang C, Wang M, et al. Dezocine for preventing postoperative pain: a meta-analysis of randomized controlled trials. PLoS One. 2015;10: e136091.

33 Bian X, Zhou R, Yang Y, et al. Divergent effect of Dezocine, morphine and Sufentanil on intestinal motor function in rats. Int J Med Sci. 2015;12:848-52.

Ready to submit your research? Choose BMC and benefit from:

- fast, convenient online submission

- thorough peer review by experienced researchers in your field

- rapid publication on acceptance

- support for research data, including large and complex data types

- gold Open Access which fosters wider collaboration and increased citations

- maximum visibility for your research: over $100 \mathrm{M}$ website views per year

At $\mathrm{BMC}$, research is always in progress.

Learn more biomedcentral.com/submissions 